\title{
Production Forecasting of Petroleum Reservoir applying Higher-Order Neural Networks (HONN) with Limited Reservoir Data
}

\author{
Chithra Chakra N C \\ College of Engineering \\ University of Petroleum \& \\ Energy Studies \\ Dehradun, India
}

\author{
Ki-Young Song \\ Department of Mechanical \\ Engineering \\ The University of Tokyo \\ Japan
}

\author{
Deoki N Saraf \\ College of Engineering \\ University of Petroleum \& \\ Energy Studies \\ Dehradun, India
}

\author{
Madan M Gupta \\ College of Engineering \\ University of Saskatchewan \\ Saskatoon, Saskatchewan \\ Canada
}

\begin{abstract}
Accurate and reliable production forecasting is certainly a significant step for the management and planning of the petroleum reservoirs. This paper presents a new neural approach called higher-order neural network (HONN) to forecast the oil production of a petroleum reservoir. In HONN, the neural input variables are correlated linearly as well as nonlinearly, which overcomes the limitation of the conventional neural network. Hence, HONN is a promising technique for petroleum reservoir production forecasting without sufficient network training data. A sandstone reservoir located in Gujarat, India was chosen for simulation studies, to prove the efficiency of HONNs in oil production forecasting with insufficient data available. In order to reduce noise in the measured data from the oil field a pre-processing procedure that consists of a low pass filter was used. Also an autocorrelation function (ACF) and cross-correlation function $(\mathrm{CCF})$ was employed for selecting the optimal input variables. The results from these simulation studies show that the HONN models have enhanced forecasting capability with higher accuracy in the prediction of oil production.
\end{abstract}

\section{Keywords:}

Production forecasting, reservoir performance, higher-order neural network, higher-order synaptic operation.

\section{INTRODUCTION}

An important phase in the field of petroleum reservoir engineering is concerned with the forecasting of oil production from the reservoir. This estimation of reserves in the petroleum reservoirs involves massive investment of money, time and technology under a wide range of operating and maintenance scenarios such as well operations and completion, artificial lift, workover, production, and injection operations. A fairly precise estimation of oil quantity in the reservoir is in demand; however, the rock and fluid properties of the reservoirs are highly nonlinear and heterogeneous in nature. Therefore, it is difficult to estimate an accurate upcoming oil production. The oil production from a reservoir depends on many static and dynamic parameters such as porosity and permeability of rocks (static parameters), and fluid saturation and pressure in the reservoir (dynamic parameters). When these static and dynamic parameters are available, the forecasting of oil production of a reservoir would be more accurate. However, all the parameter data are not always available. This limited data access from the oil fields lessens the accuracy of production forecasting.
In the past, several forecasting methods have been developed from decline curve analysis to soft computing techniques ${ }^{[1]}$. For the past few decades, artificial intelligence has been extensively applied such as neural computing, fuzzy inference systems and genetic algorithms in petroleum industries because of its potential to handle the nonlinearities and time-varying situations ${ }^{[2]}$. Neural networks $(\mathrm{NN})$ is one of the most attractive methods of artificial intelligence to cope with the nonlinearities in production forecasting ${ }^{[3]}$ as well as in parameter estimation ${ }^{[4]}$ due to its ability to learn and adapt to new dynamic environments. Numerous researches have shown successful implementation of NN in the field of oil exploration and development such as pattern recognition in well test analysis ${ }^{[5]}$, reservoir history matching ${ }^{[6]}$, prediction of phase behavior ${ }^{[7]}$, prediction of natural gas production in the United States ${ }^{[8]}$ and reservoir characterization ${ }^{[2]}$ by mapping the complex nonlinear input-output relationship. In conventional NN model, each neural unit (neuron) performs linear synaptic operation of neural inputs and synaptic weights. Later, extensive researches on NN and applications have been studied by Lee, et al. ${ }^{[9]}$, Rumelhart and McClelland ${ }^{[10]}$, Giles and Maxwell ${ }^{[11]}$, Gosh and Shin ${ }^{[12]}$, Homma and Gupta $^{[13]}$, Gupta, et al. ${ }^{[14]}$, Redalapalli ${ }^{[15]}$, Song ${ }^{[16]}$, Tiwari ${ }^{[17]}$. The innovative neural structure embeds higher-order synaptic operations (HOSO). Furthermore, the $\mathrm{NN}$ with HOSO architecture was introduced and named as Higher-order neural network $(\mathrm{HONN})^{[14],[18]}$. The exclusive feature of HONN is the expression of the correlation of neural inputs by computing products of the inputs. It has been found that HONN has significant advantages over conventional NN such as faster training, reduced network size, and smaller forecasting errors ${ }^{\text {[15], [16], [17], [19]. }}$

This paper presents a new neural approach by employing HONN to forecast oil production from an oil field reservoir with limited parameter data: i) oil production data and ii) oil, gas and water production data. Two case studies are carried out to verify the potential of the proposed neural approach with the limited available parameters from an oil field in Gujarat, India. In case study-1, only one dynamic parameter data, oil production data, are used for forecasting, whereas in case study-2, three dynamic parameter data, oil, gas and water production data are used for forecasting. A pre-processing step is included for the preparation of neural inputs. The details are explained in the succeeding sections. 


\section{Neural Networks (NN) and its Extension to Higher-order Neural Networks (HONN)}

Neural networks (NN) are composed of several layers of neural units (neurons): input layer, hidden layers and output layer. A neural unit is structured mainly with two operations: synaptic operation for weighting, and somatic operation for mapping. In a conventional neural unit, the weighting process is operated with linear correlation of neural inputs, $\mathrm{x} \_\mathrm{a}=\left(\mathrm{x} \_0, \mathrm{x} \_1, \mathrm{x} \_2, \ldots \llbracket, \mathrm{x} \rrbracket \_\mathrm{n}\right) \in \mathrm{R}^{\wedge}(\mathrm{n}+1) \quad\left(\mathrm{x} \_0\right.$ is bias $)$, and neural weights, w_a $=\left(w_{-} 0, w_{-} \_1, w_{-} 2, \ldots \llbracket, w \rrbracket \_n\right) \in R^{\wedge}(n+1)$ $\left(\mathrm{w} \_0=1\right)$. The linear correlation can be expressed mathematically as

$$
v=w_{0} x_{0}+\sum_{i=1}^{n} w_{i} x_{i}
$$

However, in the nature, the correlation of neural inputs and neural weights is not simply linear, but rather related nonlinearly. This observation introduced a nonlinear (higherorder) synaptic operation, and $\mathrm{NN}$ with the higher-order synaptic operation (HOSO) (see Figure 1) was developed and named as higher-order neural networks (HONN)[19], [20], [21]. HOSO of HONN embraces the linear correlation (conventional synaptic operation) as well as the higher-order correlation of neural inputs with synaptic weights (up to nthorder correlation).

An nth order HOSO is defined as

$$
\begin{aligned}
& v=w_{0} x_{0}+\sum_{i_{1}=1}^{n} w_{i_{1}} x_{i_{1}}+ \\
& +\sum_{i_{1}=1}^{n} \sum_{i_{2}=i_{1}}^{n} w_{i_{1} i_{2}} x_{i_{1}} x_{i_{2}}+\ldots \\
& +\sum_{i_{1}=1}^{n} \sum_{i_{2}=i_{1}}^{n} \ldots \sum_{i_{N}=i_{N-1}}^{n} w_{i_{1} i_{2} \ldots i_{N}} x_{i_{1}} x_{i_{2}} \ldots \ldots x_{i_{N}}
\end{aligned}
$$

and the somatic operation, which yields the neural output, is defined as

$$
y=\varnothing(v)
$$

In this paper, HOSO have been used up to third-order. The first-order (conventional linear correlation), the second-order and the third-order synaptic operations are called linear synaptic operation (LSO), quadratic synaptic operation (QSO) and cubic synaptic operation (CSO), respectively are applied.

The higher-order neural network (HONN) is illustrated in Figure 2. HONN consists of multiple interconnected layers: input layer, hidden layers and output layer. The input layer conveys n number of input data to the first hidden layer. Each hidden layer includes different number of neurons, and consequently the output layer contains $\mathrm{m}$ neurons. The number of the hidden layers and the number of neurons in each hidden layer can be assigned after careful investigation for different applications.

HONN is trained by an error based algorithm in which synaptic weights (connection strength) are adjusted to minimize the error between desired and neural outputs[19], [20], [21]. Let $x(k) \in R^{\wedge} n$ be the neural input pattern at time step $\mathrm{k}=1,2 \ldots \mathrm{n}$ corresponding to desired output $\mathrm{y} \_\mathrm{d}(\mathrm{k}) \in \mathrm{R}^{\wedge} 1$ and neural output $\mathrm{y}(\mathrm{k})$. The error of a pattern can be calculated as

$$
e(k)=y(k)-y_{d}(k)
$$

The overall error for an epoch $\mathrm{E}(\mathrm{k})$ is defined as

$$
E(k)=\frac{1}{2} e^{2}(k)
$$

The overall error (squared error) is minimized by updating the weight matrix $\mathrm{w}_{\mathrm{a}}$ as

$$
\boldsymbol{w}_{a}(k+1)=\boldsymbol{w}_{a}(k)+\Delta \boldsymbol{w}_{a}(k)
$$

where the change in weight matrix is denoted by $\Delta \mathrm{w}_{\mathrm{a}}(\mathrm{k})$ which is proportional to the gradient of the error function $\mathrm{E}(\mathrm{k})$ as

$$
\Delta \boldsymbol{w}_{a}(k)=-\alpha \frac{\partial E(k)}{\partial \boldsymbol{w}_{a}(k)}
$$

where $\alpha>0$ is the learning rate which effects the performance of the algorithm during the updating process. The details can be found in the reference by Gupta et. al [14].

\section{Model Performance Evaluation Criteria}

Several statistical methods have been used to evaluate the performance of neural networks in the literature. In these studies, the following performance parameters are applied to substantiate the statistical accuracy of the performance of HONNs: root mean square error (RMSE) and mean absolute percentage error (MAPE). These performance measurements are commonly used evaluation criteria in assessing the model performance. They indicate the deviation of prediction of applied HONN models, and are defined as

Root mean square error (RMSE):

\section{$R M S E$}

$$
=\sqrt{\frac{1}{n} \sum_{i=1}^{n}\left(y_{i}^{o b s}-y_{i}^{p r e d}\right)^{2}}
$$

Mean Absolute Percentage Error (MAPE): 
$M A P E=\frac{100}{n} \sum_{i=1}^{n}\left|\frac{y_{i}^{o b s}-y_{i}^{\text {pred }}}{y_{i}^{o b s}}\right|$

where $y^{o b s}$ is the observed data, $y^{\text {pred }}$ is the predicted data, and $\mathrm{n}$ is the number of data points.

Regression analysis is carried out for demonstrating the HONN model performance during validation phase. The model performance assessed by regression analysis is illustrated using regression or parity plots. Using regression plots one can assess how consistent is the forecasted data with the observed data. It is considered that if the regression of a model follows $\mathrm{Y}=\mathrm{T}$ line more closely the model can perform better prediction (see Figure 6), since the $\mathrm{Y}=\mathrm{T}$ lines represent the best fit.

In order to illustrate the consistency in performance of HONN model towards forecasting the production data, we have used two performance measurement metrics. The results obtained using both metrics are different in their calculated values, but the significance of each metrics is similar in performance measurement of HONN model. Since the production data used as neural input, preprocessed data and raw data have different scales, it is preferable to use MAPE for estimating the relative error ${ }^{[22]}$.

\section{Pre-Processing: Optimal Selection of Input Variables}

Before performing a prediction by HONN, it is important and necessary to preprocess the available input data because of two main reasons: i) noise reduction and ii) proper selection of input variables. The measured oil production data from the field include noise. It is not appropriate to use the raw data for neural network training because $\mathrm{NN}$ requires extremely low learning rates. A preprocessing of the raw experimental production data was, therefore, incorporated in all cases to minimize measurement errors. Moving average is a type of low pass filter that transforms the time series monthly production data into smooth trends. This filter does weighted averaging of past data points in the time series production data within the specified time span to generate a smoothed estimate of a time series. The time span of moving average depends on the analytical objectives of the problem. For case studies, we used moving average filter with a time span of five-points since it is found to be optimal for reducing the random noise by retaining the sharpest step response associated with production data. Moving average filter is the simplest and perhaps optimal filter that can be used for time domain signals as reported by Smith ${ }^{[23]}$.

After noise reduction process, auto-correlation analysis is carried out to find optimal input variables. Determining the significant input variables is an important task in the process of training HONN model for production forecasting. A thorough understanding of dynamics in petroleum reservoir is necessary to avoid missing key input variables and prevent introduction of spurious input variables that create confusion in training process. Currently, there is no strict rule for the selection of input variables. Most of the heuristic methods for selecting input variables are ad-hoc or have experimental basis. In this paper, the significant input variables are selected by employing auto-correlation function (ACF) for single parameter data and cross-correlation function $(\mathrm{CCF})$ for multiple parameter data. These statistical methods provide the correlation between different input variables by identifying potentially influencing variables at different time lags. The idea behind these statistical methods is to investigate the dependence between the input variables.

$\mathrm{ACF}$ is a set of auto-correlation coefficients arranged as a function of observations separated in time. It is a common tool for assessing the pattern in time series production data at numerous time lags. Consider the observations $\quad x_{t}$ and $x_{t+k} ; t=1,2, \ldots, n$; then the autocorrelation coefficient $r_{(k)}$ at lagk can be calculated using Eq.10

$$
\begin{aligned}
r_{(k)}=\frac{1}{n} \sum_{t=1}^{n-k}\left(x_{t}-\bar{x}\right) & \\
& -\left(x_{t+k}-\bar{x}\right) ; \bar{x} \\
& =\sum_{t=1}^{n} x_{t}
\end{aligned}
$$

The CCF is a set of cross-correlation coefficients arranged as a function of observations of one or more time series data at different time steps (lag). Consider two time series $x_{t}$ and $y_{t}, t=1,2, \ldots, n$; the time series $\mathrm{y}_{\mathrm{t}}$ may be correlated to the past lags of time series $x_{t}$ and this can be calculated using Eq. 11. Here $r_{x y}(k)$ is the cross-correlation coefficient between $x_{t}$ and $y_{t}$ and $k$ is the lag. This means measurements in the variable $y$ are lagging or leading those in $x$ by $k$ time steps.

$$
\begin{aligned}
& r_{x y(k)}
\end{aligned}
$$

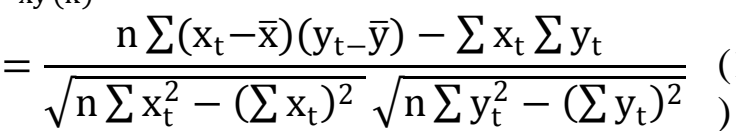

The present study is based only on positive lags. The presence of positive lagk between $x_{t}$ and $y_{t}$ indicates that the relationship between these time series will be most significant when the data in $x$ at time $t$ are related to data in $y$ at time $t+k$.

In case study-1, ACF is applied to determine the optimal input variables because only monthly oil production data is used for forecasting. In case study-2, three parameter data, oil, gas and water production data, are available as input and hence CCF is used to determine the optimal input variables.

\section{THE RESERVOIR UNDER STUDY}

The simulation studies are carried out with the production data from a real oil field reservoir which has 94 months of production history. The oil field is located in southwestern part of Cambay Basin in Gujarat. This field consists of total 8 oil producing wells. The structure of the field trends NNW-SSE in direction and bounded by a fault on either side, which separates the structure from the adjoining lows. The reservoir structure is controlled by East-West trending normal fault in the north, and it narrows down towards south. The field composed of 3 sandstone layers (L-1, L-2, and L-3) having varying thickness up to $25 \mathrm{~m}$, and the layers are separated by thin shales with thickness in the range of $1 \mathrm{~m}$ to 
$2 \mathrm{~m}$. The graphical presentation of oil field reservoir for this study is shown in Figure 3.

The initial reservoir pressure was recorded as 144 $\mathrm{kg} / \mathrm{cm}^{2}$ at $1397 \mathrm{~m}$. The quantity of reserved oil inplace was 2.47MMt, and the cumulative oil production until September 2009 was $0.72 \mathrm{MMt}$ which is $29.1 \%$ of the inplace reserve and $64.5 \%$ of ultimate reserve. The field started producing oil from February 2000 through Well-1 at a rate of $58 \mathrm{~m}^{3} / \mathrm{d}$ and December 2000 through Well-2. The initial reservoir pressure recorded at Well-1 was $144.6 \mathrm{~kg} / \mathrm{cm}^{2}$ at $1385 \mathrm{~m}$. From the production performance, the cumulative productions of oil, gas water from Well-1 till September 2009 are 0.156MMt, $8.1 \mathrm{MMm}^{3}$, and $7.2 \mathrm{Mm}^{3}$, respectively. Later, other wells (Well-3 Well-8) were drilled and put on production in different years until 2009.

The interest of this study is in forecasting the oil production from the oldest well of the field, Well-1. Two cases are studied for oil production forecasting using: i) only oil production data and ii) oil, water and gas production data. Tables 1. (a) and (b) present the raw and smoothed monthly oil, gas and water productions ratios corresponding to each maximum production values of Well-1 from 2001 to 2009 . For an efficient training for HONN, the monthly production ratios were calculated using the maximum production of products $\left(3000 \mathrm{~m}^{3} /\right.$ month for oil, $150000 \mathrm{~m}^{3} /$ month for gas, and $1500 \mathrm{~m}^{3} /$ month for water) through the 9 years production history of Well-1.

\subsection{Structure of HONN}

For this study, a number of design factors for HONN were considered such as selection of neural structure (order of synaptic operation), numbers of neurons and hidden layers. Also, different mapping functions (somatic operation) were selected after careful investigation in each layer: a sigmoidal (hyperbolic tangent) function for hidden layers and a linear function for the output layer.

Three synaptic operations, linear synaptic operation (LSO), quadratic synaptic operation (QSO) and cubic synaptic operation (CSO) were employed for this study. Only one hidden layer was used since it resulted in the best output for time sequence applications such as forecasting [17], and different number of neurons $(1 \sim 5)$ in the hidden layer were applied. Each HONN model was run with learning rate of 0.01 and different initial synaptic weights. The learning rate was dynamically updated by multiplying with 1.05 for decreasing error and with 0.7 for increasing error. The preprocessed data were divided into three segments for training, testing and validation. The number of data sets used for training and testing of HONN model for each case study varied; however, last 16 months (month 78 94) data are used to validate HONN models for case study. Each model was performed for 200 epochs for training and testing, and then, a validation was carried out.

The network was designed for prediction mode. If the input to the network was production data at time $t$, then the output is taken to at time $t+1$. During the network training, the network output was compared with the production data at time $t+1$ and the error was used to correct the synaptic weights. This means that the network is used as a one-stepahead predictor. This is necessary for production forecasting.

\subsection{Case Study-1}

The monthly oil production ratios from month 1 to month 94 were used for oil production forecasting as listed in Table $1 \mathrm{a}$. In the pre-processing stage, the oil production ratio data were smoothed using a five point moving average filter. The smoothed oil production data are presented in Table $1 \mathrm{~b}$. The graphical representation of original oil production data and smoothed data are shown in Figure 4. As seen in the figure, the high peaks of the data were smoothed. After the smoothing process, the auto-correlation of the oil production data was calculated by auto-correlation function (ACF). The $\mathrm{ACF}$ plot of oil production after smoothing is presented in Figure 5. The ACF shows that the lags from lag0 to lag21 have some correlation within the $95 \%$ confidence level (outside of the blue lines, positive region). From the ACF plot, it was identified that lag1 and lag2 have the most significant correlation which means that the input variables in these lags are the optimal to train HONN. In view of above, we trained HONN to forecast oil production based on three scenarios:

1) using only lag1 (single lag1)

2) using only lag2 (single lag2)

3) using lag1 and lag2 (accumulated lag2)

\section{1) HONN using Single Lag1}

In scenario 1 , first 51 months data were used for training and next 26 months data for testing. The lag1 data presented to HONN after pre-processing are given in Table 2 . In this table, input corresponds to oil productions rates from Well-1 and target corresponds to the oil production data that has been advanced by one step. The regressions of the best HONN models with LSO, QSO and CSO for the validation set of data are presented in Figures 6. (a), (b), (c); respectively.

The simulation results from HONN model in terms of RMSE and MAPE are show in Table 3. The selection criteria for a better model are lower values of MAPE and RMSE. From simulation results, the best model was HONN with LSO having five neurons in the hidden layer. The performance indices of best model shows HONN with LSO resulted in MAPE $=13.86 \%$. With CSO, MAPE $=14.89 \%$ was achieved with three neural units in the hidden layer, and MAPE $=15.98 \%$ was achieved with QSO having five neurons in the hidden layer.

\section{2) HONN using Single Lag2}

For scenario 2, first 50 months data for training and next 26 months data for testing were selected applying single lag2 after pre-processing and the data were arranged as listed in Table 4. In single lag2, the target data used for HONN are advanced by 2 time steps.

Table 5 lists the simulation results using single lag2 from HONN models. The performance indices of the best HONN model with LSO resulted in MAPE $=18.6$. However, the HONNs with QSO and CSO did not result in acceptable outputs with single lag2. Parity plots are not included here for brevity.

3) HONN using accumulated Lag2 
For this scenario, accumulated lag2 (lag1 and lag2), the input, train and test data are shown in Table 6. Input-1 and Input- 2 in Table 6 corresponds to oil production from Well-1 at time lag1 and time lag-2.

The simulation results using accumulated lag2 are presented in Table 7. From this table it is seen that HONN with LSO having two neurons in the hidden layer resulted in MAPE $=13.671 \%$ and $\mathrm{RMSE}=0.067$. These results are comparable to those obtained in scenario1 but the standard deviations are higher, meaning, thereby, that using lag2 in any form does not help the predictions.

For case study-1, the overall performance measure shows that HONN with LSO resulted in good performances by yielding a stable value between the range of, RMSE = $0.066 \sim 0.084$ and $M A P E=13 \sim 18 \%$ with different configurations of neurons in the hidden layer.

\subsection{Case Study-2}

For this simulation study, monthly oil, gas and water production rates from Well-1 from September 2001 to March 2009 were used for oil production forecasting. Table 1 $\mathrm{a}$ and $\mathrm{b}$, present the monthly oil, gas and water production data ratios for 94 months before and after smoothing.

This case study shows how additional input parameters (gas and water production) influence the performance of HONN model in forecasting oil production. The production data were preprocessed by applying smoothing process and cross-correlation. The smoothing process was carried out by a moving averaging filter with five sequence data points as discussed earlier. Oil, gas and water production ratios, before and after smoothing, are graphically presented in Figure 4 (oil), Figure 7.a (gas) and Figure 7.b (water). After that, smoothed data were used to find crosscorrelation function $(\mathrm{CCF})$ between three production data as shown in Figure 8 . The significant input variables were determined using CCF by identifying the correlation between oil and other components. It is observed from the CCF plot that the correlations between oil and oil (auto-correlation), oil and gas, oil and water are significant at lag1; lag1; and lag2, and lag23, respectively (Table 8 ). A total of 4 input vectors were identified for monthly oil production forecasting by HONN model. The smoothed data from Table $1 \mathrm{~b}$. were arranged applying the lags obtained from the CCF plot as presented in Table 8. Input1 represents the correlation of oil at lag1, input 2 and input 3 refers to the correlation of oil with gas production at lag1 and lag2, and input 4 represents the correlation of oil with water production at lag23 (see Table 9 for the input and output data for this case).

Table 10 presents the results from HONN models with its performance measure in terms of RMSE and MAPE for different configurations of neurons in the hidden layer and synaptic operation. In this case study, the best model resulted in $\mathrm{MAPE}=15.13 \%$, and $\mathrm{RMSE}=0.069$ by $\mathrm{HONN}$ with QSO having four neurons in the hidden layer.

\section{PRODUCTION FORECASTING}

Using the HONN, one-step-ahead production model, for Well-1 in the Tarapur block of Cambay Basin, predictions were made for 16 months (from February 2008 to September 2009 (i.e month 77 94) beyond the date used for model development and its training. A comparison of the prediction by the best HONN model with LSO using single lag1 with the actual oil production is presented by Figure 9. As seen in this model, the match is satisfactory for the first 13 months.

\section{DISCUSSIONS}

From the case studies, the performance evaluation criteria indicates that the better oil production forecasting can be achieved using HONN with LSO with only one input parameter i.e. oil production data. In this study, the selection of lag time is an important factor that influences the forecasting results. Auto-correlation function (ACF) indicates that the most significant lag for oil production forecasting with only one parameter (oil production) is lag1, and HONN with LSO yields the best forecasting oil production in this case. Intuitively, it can be expected that QSO and CSO would result in better outcome than that of LSO. However, this case study comes up with opposite result. This can be explained by recalling that only one input parameter (oil production), used in case study-1, does not generate complex correlation with target parameter (oil production to be predicted). Thus, in this case, linear combination of synaptic operations could result in better prediction. However, in case study-2, the three input parameters, namely; oil, gas and water production rates may generate nonlinearity and heterogeneity between input and target parameters. In this case, the higher-order synaptic operations, QSO and CSO, would be better suited to forecast the oil production.

It is observed that the performance of HONN with LSO in the case study-1 shows less MAPE than that in the case study-2. One would expect that since gas and water production rates are intimately connected with oil production rate, case study-2 ought to have shown better match or less MAPE. The contrary results may be attributed to the possibility that the noise in gas and water production measurements even after filtering may have overshadowed the advantage gained by added input information. Additionally, the number of input patterns in case study-1 is higher than that in the case study-2. The reduction in the number of input patterns for training HONN in the case study- 2 is caused by the number of lags. In the case study-2, the highest number of lags is 23 which reduce the input pattern numbers as $\mathrm{P}-23$ where $\mathrm{P}$ is the number of initial input patterns. The patterns for oil, gas and water productions are selected based on crosscorrelated pattern Overall, it can be inferred that for the application of HONN for forecasting, the number of input variables is one of the significant factors in determining the order of synaptic operation.

Mean absolute percentage error (MAPE) is a measure of uncertainty in forecasting of oil production from a single well. A high value of $13 \sim 15 \%$ is indicative of lack of enough input information to the HONN model. One important information that is missing is clearly the well pressure (bottom hole pressure). Another one is the presence of other wells in its vicinity and their production pattern which, to some extent, could have been reflected by the well pressure. It may, therefore, be anticipated that if we were to use this procedure for all the five wells in this reservoir, MAPE will be reduced. Preliminary work on these lines indicates a reduction by as much as $75 \%$ in the MAPE. This work will be published at a future date when completed. 


\section{CONCLUSION}

A new neural approach for forecasting oil production using higher-order neural network (HONN) was proposed in this paper. Two case studies were carried out with the data from an oil field situated at Cambay basin, Gujarat, India, to demonstrate the forecasting ability of HONN models.

The simulation study indicates that HONN has high potential for application in oil production forecasting with limited available input parameters of petroleum reservoirs. The HONN methodology applied to forecasting of oil production yielded 13.86 and 15.13 of MAPE in the two cases examined. In order to achieve the MAPE, two pre-processing procedures were found to be beneficial: i) noise reduction and ii) selection of optimal input variables. In this study, a low pass filtering process, a 5-point moving averaging filter, for noise reduction was used. Auto-correlation function for single input parameter and cross-correlation function for multiple input parameters were employed to determine the most significant correlation between the parameters. Considering the limited available input parameters for forecasting, the performance indicates that $\mathrm{HONN}$ has a high potential to overcome this limitation. Also, for complicated input patterns, such as in the cast study-2, the higher combination of the input products reduces the computational cost, which yields faster results.

\section{ACKNOWLEDGMENTS}

We thank Institute of Reservoir Studies, ONGC, India for their support in providing field production data for this work. The work of first author was financially supported by Canadian Commonwealth Fellowship and University of Petroleum and Energy Studies. The fourth author acknowledges the fund provided by NSERC Discovery Grant. The valuable comments and recommendations from the reviewers are acknowledged.

\section{REFERENCES}

[1] D. Tamhane, P. M. Wong, F. Aminzadeh, and M. Nikravesh, "Soft Computing for Intelligent Reservoir Characterization," in SPE Asia Pacific Conference on Integrated Modelling for Asset Management Yokohama, Japan, 2000, pp. 1-11.

[2] S. D. Mohaghegh, "Recent Developments in Application of Artificial Intelligence in Petroleum Engineering," Journal of Petroleum Technology, vol. 57, pp. 86-91, 2005.

[3] W. W. Weiss, R. S. Balch, and B. A. Stubbs, "How Artificial Intelligence Methods Can Forecast Oil Production," in SPE/DOE Improved Oil Recovery Symposium, Tulsa, Oklahoma: Society of Petroleum Engineers, 2002, pp. 1-16.

[4] F. Aminzadeh, J. Barhen, C. W. Glover, and N. B. Toomarian, "Reservoir Parameter Estimation Using a Hybrid Neural Network," Comput. Geosci., vol. 26, pp. 869-875, 2000

[5] A. U. Al-Kaabi and W. J. Lee, "Using Artificial Neural Networks To Identify the Well Test Interpretation Model " SPE Formation Evaluation, vol. 8, pp. 233-240, 1993.

[6] C. Maschio, C. P. V. de Carvalho, and D. J. Schiozer, "A New Methodology to Reduce Uncertainties in Reservoir Simulation Models Using Observed Data and Sampling
Techniques," Journal of Petroleum Science and Engineering, vol. 72, pp. 110-119, 2010.

[7] W. A. Habiballah, R. A. Startzman, and M. A. Barrufet, "Use of Neural Networks for Prediction of Vapor/Liquid Equilibrium K-Values for Light-Hydrocarbon Mixtures," SPE Reservoir Engineering, vol. 11, pp. 121-126, 1996.

[8] S. M. Al-Fattah and R. A. Startzman, "Predicting Natural Gas Production Using Artificial Neural Network," in SPE Hydrocarbon Economics and Evaluation Symposium, Dallas, Texas: Society of Petroleum Engineers, 2001, pp. 1-11.

[9] Y. C. Lee, G. Doolen, H. H. Chen, G. Z. Sun, T. Maxwell, H. Y. Lee, and C. L. Giles, "Machine Learning Using a Higher Order Correlation Network," Phys. D, vol. 2, pp. 276 - 306, 1986.

[10] D. E. Rumelhart and J. L. McClelland, Parallel Distributed Processing: Explorations in the Microstructure of Cognition. Cambridge, MA: The MIT Press, 1986.

[11] C. L. Giles and T. Maxwell, "Learning, Invariance, and Generalization in High-Order Neural Networks," Applied Optics, vol. 26, pp. 4972-4978., 1987.

[12] J. Gosh and Y. Shin, "Effcient Higher-Order Neural Networks For Classification And Function Approximation," International Journal of Neural Systems, vol. 3, pp. 323-350., 1992.

[13] N. Homma and M. M. Gupta, "Superimposing Learning for Backpropagation Neural Networks," Bulletin of College of Medical Sciences, Tohoku University, vol. 11, pp. 253-259, 2002.

[14] M. M. Gupta, L. Jin, and N. Homma, Static and Dynamic Neural Networks: From Fundamentals to Advanced Theory, 1 ed.: Wiley - IEEE Press, 2003.

[15] S. K. Redlapalli, "Development of Neural Units with Higher-order Synaptic Operations and Their Applications to Logic Circuits and Control Poblems," in Department of Mechanical Engineering: University of Saskatchewan, Canada, 2004.

[16] K.-Y. Song, M. M. Gupta, and D. Jena, "Design of An Error-Based Robust Adaptive Controller," in Systems, Man and Cybernetics, 2009. SMC 2009. IEEE International Conference on, 2009, pp. 2386-2390.

[17] M. K. Tiwari, K. Y. Song, C. Chatterjee, and M. M. Gupta, "River-flow Forecasting Using Higher-order Neural Networks," Journal of Hydrologic Engineering, vol. 17, pp. 1-12, 2012.

[18] Z.-G. Hou, K.-Y. Song, M. M. Gupta, and M. Tan, "Neural Units with Higher-Order Synaptic Operations for Robotic Image Processing Applications," Soft Comput., vol. 11, pp. 221-228, 2006.

[19] M. M. Gupta, N. Homma, Z.-G. Hou, A. M. G. Solo, and I. Bukovsky, "Higher Order Neural Networks: Fundamentals Theroy and Appplications," in Artificial Higher-Order Neural Networks for Computer Science and Engineeing: Trends for emerging Applications, $\mathrm{M}$. Zhang, Ed.: Information Science Reference, 2010, pp. 397-422.

[20] M. M. Gupta, "Correlative Type Higher-Order Neural Units with Applications," in Automation and Logistics, 2008. ICAL 2008. IEEE International Conference, 2008, pp. 715-718.

[21] M. M. Gupta and D. H. Rao, Neuro-Control SystemsTheory and Applications: IEEE Neural Networks Council, 1993.

[22] A. Azadeh, S. F. .Ghaderi, and S. Sohrabkhani, "Forcasting Electrical Consumption by Integration of 
Neural Network, Time Series and ANOVA," Applied Mathematics and Computation, 2006.

[23] S. W. Smith, The Scientist and Engineer's Guide to Digital Signal Processing, 1997.

Table 1 a. Ratio of monthly oil, gas and water production to corresponding maximum production value of nine years from Well-1.

\begin{tabular}{|c|c|c|c|c|c|c|c|}
\hline Months & Oil & Gas & Water & Months & Oil & Gas & Water \\
\hline 1 & 0.982 & 0.982 & 0.096 & 48 & 0.240 & 0.164 & 0.920 \\
\hline 2 & 0.930 & 0.930 & 0.135 & 49 & 0.241 & 0.163 & 0.965 \\
\hline 3 & 0.950 & 0.950 & 0.245 & 50 & 0.198 & 0.140 & 0.625 \\
\hline 4 & 0.907 & 0.907 & 0.244 & 51 & 0.192 & 0.150 & 0.670 \\
\hline 5 & 0.862 & 0.862 & 0.144 & 52 & 0.200 & 0.160 & 0.653 \\
\hline 6 & 0.704 & 0.704 & 0.074 & 53 & 0.174 & 0.131 & 0.603 \\
\hline 7 & 0.922 & 0.922 & 0.060 & 54 & 0.157 & 0.110 & 0.699 \\
\hline 8 & 0.972 & 0.972 & 0.076 & 55 & 0.147 & 0.102 & 0.686 \\
\hline 9 & 0.874 & 0.884 & 0.057 & 56 & 0.101 & 0.073 & 0.810 \\
\hline 10 & 0.927 & 0.914 & 0.052 & 57 & 0.097 & 0.073 & 0.785 \\
\hline 11 & 0.818 & 0.806 & 0.287 & 58 & 0.150 & 0.108 & 0.602 \\
\hline 12 & 0.764 & 0.753 & 0.326 & 59 & 0.091 & 0.065 & 0.386 \\
\hline 13 & 0.884 & 0.872 & 0.152 & 60 & 0.123 & 0.088 & 0.557 \\
\hline 14 & 0.862 & 0.849 & 0.134 & 61 & 0.205 & 0.148 & 0.666 \\
\hline 15 & 0.813 & 0.801 & 0.111 & 62 & 0.207 & 0.149 & 0.622 \\
\hline 16 & 0.624 & 0.618 & 0.180 & 63 & 0.205 & 0.145 & 0.664 \\
\hline 17 & 0.393 & 0.387 & 0.542 & 64 & 0.133 & 0.096 & 0.516 \\
\hline 18 & 0.507 & 0.500 & 0.410 & 65 & 0.102 & 0.071 & 0.635 \\
\hline 19 & 0.517 & 0.386 & 0.366 & 66 & 0.114 & 0.076 & 0.701 \\
\hline 20 & 0.536 & 0.401 & 0.375 & 67 & 0.107 & 0.073 & 0.686 \\
\hline 21 & 0.490 & 0.368 & 0.420 & 68 & 0.110 & 0.073 & 0.688 \\
\hline 22 & 0.486 & 0.364 & 0.537 & 69 & 0.127 & 0.089 & 0.626 \\
\hline 23 & 0.478 & 0.359 & 0.552 & 70 & 0.059 & 0.040 & 0.224 \\
\hline 24 & 0.396 & 0.297 & 0.688 & 71 & 0.124 & 0.093 & 0.612 \\
\hline 25 & 0.462 & 0.346 & 0.369 & 72 & 0.118 & 0.089 & 0.644 \\
\hline 26 & 0.454 & 0.341 & 0.529 & 73 & 0.050 & 0.038 & 0.784 \\
\hline 27 & 0.474 & 0.356 & 0.498 & 74 & 0.127 & 0.098 & 0.645 \\
\hline 28 & 0.451 & 0.338 & 0.735 & 75 & 0.117 & 0.090 & 0.473 \\
\hline 29 & 0.460 & 0.242 & 0.665 & 76 & 0.109 & 0.083 & 0.489 \\
\hline 30 & 0.440 & 0.264 & 0.712 & 77 & 0.129 & 0.099 & 0.572 \\
\hline 31 & 0.352 & 0.211 & 0.636 & 78 & 0.160 & 0.122 & 0.590 \\
\hline 32 & 0.350 & 0.210 & 0.643 & 79 & 0.142 & 0.108 & 0.556 \\
\hline 33 & 0.315 & 0.189 & 0.671 & 80 & 0.147 & 0.114 & 0.555 \\
\hline 34 & 0.326 & 0.196 & 0.690 & 81 & 0.165 & 0.130 & 0.490 \\
\hline 35 & 0.336 & 0.245 & 0.651 & 82 & 0.141 & 0.111 & 0.547 \\
\hline 36 & 0.248 & 0.170 & 0.904 & 83 & 0.162 & 0.126 & 0.507 \\
\hline 37 & 0.351 & 0.235 & 0.725 & 84 & 0.095 & 0.073 & 0.570 \\
\hline 38 & 0.344 & 0.230 & 0.692 & 85 & 0.090 & 0.067 & 0.546 \\
\hline 39 & 0.165 & 0.078 & 0.434 & 86 & 0.141 & 0.107 & 0.478 \\
\hline 40 & 0.166 & 0.117 & 0.432 & 87 & 0.104 & 0.080 & 0.579 \\
\hline 41 & 0.146 & 0.109 & 0.398 & 88 & 0.092 & 0.079 & 0.551 \\
\hline 42 & 0.163 & 0.121 & 0.439 & 89 & 0.076 & 0.047 & 0.539 \\
\hline 43 & 0.158 & 0.109 & 0.420 & 90 & 0.081 & 0.055 & 0.583 \\
\hline 44 & 0.173 & 0.119 & 0.419 & 91 & 0.078 & 0.050 & 0.663 \\
\hline 45 & 0.267 & 0.183 & 0.812 & 92 & 0.087 & 0.059 & 0.599 \\
\hline 46 & 0.207 & 0.142 & 0.616 & 93 & 0.009 & 0.006 & 0.159 \\
\hline 47 & 0.281 & 0.193 & 0.886 & 94 & 0.418 & 0.284 & 0.270 \\
\hline
\end{tabular}

Table 1 b. Ratio of smoothed monthly oil, gas and water production to corresponding maximum production value of nine years from Well-1.

\begin{tabular}{|c|c|c|c|c|c|c|c|}
\hline Months & Oil & Gas & Water & Months & Oil & Gas & Water \\
\hline 1 & 0.982 & 0.917 & 0.096 & 48 & 0.233 & 0.149 & 0.802 \\
\hline 2 & 0.954 & 0.890 & 0.159 & 49 & 0.230 & 0.151 & 0.813 \\
\hline 3 & 0.926 & 0.865 & 0.173 & 50 & 0.214 & 0.145 & 0.767 \\
\hline 4 & 0.871 & 0.813 & 0.168 & 51 & 0.201 & 0.139 & 0.703 \\
\hline 5 & 0.869 & 0.811 & 0.153 & 52 & 0.184 & 0.129 & 0.650 \\
\hline 6 & 0.873 & 0.815 & 0.120 & 53 & 0.174 & 0.122 & 0.662 \\
\hline 7 & 0.867 & 0.811 & 0.082 & 54 & 0.156 & 0.107 & 0.690 \\
\hline 8 & 0.880 & 0.821 & 0.064 & 55 & 0.135 & 0.091 & 0.717 \\
\hline 9 & 0.903 & 0.840 & 0.106 & 56 & 0.130 & 0.087 & 0.716 \\
\hline 10 & 0.871 & 0.808 & 0.160 & 57 & 0.117 & 0.079 & 0.654 \\
\hline 11 & 0.853 & 0.789 & 0.175 & 58 & 0.112 & 0.077 & 0.628 \\
\hline 12 & 0.851 & 0.783 & 0.190 & 59 & 0.133 & 0.091 & 0.599 \\
\hline 13 & 0.828 & 0.762 & 0.202 & 60 & 0.155 & 0.105 & 0.567 \\
\hline 14 & 0.789 & 0.727 & 0.181 & 61 & 0.166 & 0.112 & 0.579 \\
\hline 15 & 0.715 & 0.658 & 0.224 & 62 & 0.175 & 0.117 & 0.605 \\
\hline 16 & 0.640 & 0.589 & 0.275 & 63 & 0.170 & 0.114 & 0.621 \\
\hline 17 & 0.571 & 0.503 & 0.322 & 64 & 0.152 & 0.100 & 0.628 \\
\hline 18 & 0.515 & 0.428 & 0.375 & 65 & 0.132 & 0.086 & 0.640 \\
\hline 19 & 0.489 & 0.381 & 0.423 & 66 & 0.113 & 0.073 & 0.645 \\
\hline 20 & 0.507 & 0.377 & 0.422 & 67 & 0.112 & 0.071 & 0.667 \\
\hline 21 & 0.501 & 0.351 & 0.450 & 68 & 0.103 & 0.066 & 0.585 \\
\hline 22 & 0.477 & 0.334 & 0.514 & 69 & 0.105 & 0.069 & 0.567 \\
\hline 23 & 0.462 & 0.324 & 0.513 & 70 & 0.108 & 0.072 & 0.559 \\
\hline 24 & 0.455 & 0.319 & 0.535 & 71 & 0.096 & 0.065 & 0.578 \\
\hline 25 & 0.453 & 0.317 & 0.527 & 72 & 0.096 & 0.067 & 0.582 \\
\hline 26 & 0.447 & 0.313 & 0.564 & 73 & 0.107 & 0.076 & 0.632 \\
\hline 27 & 0.460 & 0.303 & 0.559 & 74 & 0.104 & 0.074 & 0.607 \\
\hline 28 & 0.456 & 0.288 & 0.628 & 75 & 0.106 & 0.076 & 0.593 \\
\hline 29 & 0.435 & 0.263 & 0.649 & 76 & 0.128 & 0.092 & 0.554 \\
\hline 30 & 0.411 & 0.236 & 0.678 & 77 & 0.131 & 0.094 & 0.536 \\
\hline 31 & 0.383 & 0.208 & 0.665 & 78 & 0.137 & 0.098 & 0.552 \\
\hline 32 & 0.357 & 0.200 & 0.670 & 79 & 0.149 & 0.107 & 0.553 \\
\hline 33 & 0.336 & 0.196 & 0.658 & 80 & 0.151 & 0.109 & 0.548 \\
\hline 34 & 0.315 & 0.189 & 0.712 & 81 & 0.151 & 0.110 & 0.531 \\
\hline 35 & 0.315 & 0.193 & 0.728 & 82 & 0.142 & 0.103 & 0.534 \\
\hline 36 & 0.321 & 0.201 & 0.732 & 83 & 0.131 & 0.095 & 0.532 \\
\hline 37 & 0.289 & 0.179 & 0.681 & 84 & 0.126 & 0.090 & 0.530 \\
\hline 38 & 0.255 & 0.155 & 0.637 & 85 & 0.118 & 0.084 & 0.536 \\
\hline 39 & 0.234 & 0.143 & 0.536 & 86 & 0.104 & 0.076 & 0.545 \\
\hline 40 & 0.197 & 0.122 & 0.479 & 87 & 0.101 & 0.071 & 0.539 \\
\hline 41 & 0.160 & 0.100 & 0.425 & 88 & 0.099 & 0.069 & 0.546 \\
\hline 42 & 0.161 & 0.107 & 0.422 & 89 & 0.086 & 0.058 & 0.583 \\
\hline 43 & 0.181 & 0.120 & 0.498 & 90 & 0.083 & 0.054 & 0.587 \\
\hline 44 & 0.194 & 0.126 & 0.541 & 91 & 0.066 & 0.040 & 0.509 \\
\hline 45 & 0.217 & 0.139 & 0.631 & 92 & 0.135 & 0.085 & 0.455 \\
\hline 46 & 0.234 & 0.149 & 0.731 & 93 & 0.171 & 0.109 & 0.343 \\
\hline 47 & 0.247 & 0.158 & 0.840 & 94 & 0.418 & 0.265 & 0.270 \\
\hline
\end{tabular}


Table 2. The train and test data used to train HONN model for scenario 1 (lag1)

\begin{tabular}{|c|c|c|c|c|c|}
\hline Months & Input & Target & Months & Input & Target \\
\hline 1 & 0.982 & 0.954 & 40 & 0.197 & 0.160 \\
\hline 2 & 0.954 & 0.926 & 41 & 0.160 & 0.161 \\
\hline 3 & 0.926 & 0.871 & 42 & 0.161 & 0.181 \\
\hline 4 & 0.871 & 0.869 & 43 & 0.181 & 0.194 \\
\hline 5 & 0.869 & 0.873 & 44 & 0.194 & 0.217 \\
\hline 6 & 0.873 & 0.867 & 45 & 0.217 & 0.234 \\
\hline 7 & 0.867 & 0.880 & 46 & 0.234 & 0.247 \\
\hline 8 & 0.880 & 0.903 & 47 & 0.247 & 0.233 \\
\hline 9 & 0.903 & 0.871 & 48 & 0.233 & 0.230 \\
\hline 10 & 0.871 & 0.853 & 49 & 0.230 & 0.214 \\
\hline 11 & 0.853 & 0.851 & 50 & 0.214 & 0.201 \\
\hline 12 & 0.851 & 0.828 & 51 & 0.201 & 0.184 \\
\hline 13 & 0.828 & 0.789 & 52 & 0.184 & 0.174 \\
\hline 14 & 0.789 & 0.715 & 53 & 0.174 & 0.156 \\
\hline 15 & 0.715 & 0.640 & 54 & 0.156 & 0.135 \\
\hline 16 & 0.640 & 0.571 & 55 & 0.135 & 0.130 \\
\hline 17 & 0.571 & 0.515 & 56 & 0.130 & 0.117 \\
\hline 18 & 0.515 & 0.489 & 57 & 0.117 & 0.112 \\
\hline 19 & 0.489 & 0.507 & 58 & 0.112 & 0.133 \\
\hline 20 & 0.507 & 0.501 & 59 & 0.133 & 0.155 \\
\hline 21 & 0.501 & 0.477 & 60 & 0.155 & 0.166 \\
\hline 22 & 0.477 & 0.462 & 61 & 0.166 & 0.175 \\
\hline 23 & 0.462 & 0.455 & 62 & 0.175 & 0.170 \\
\hline 24 & 0.455 & 0.453 & 63 & 0.170 & 0.152 \\
\hline 25 & 0.453 & 0.447 & 64 & 0.152 & 0.132 \\
\hline 26 & 0.447 & 0.460 & 65 & 0.132 & 0.113 \\
\hline 27 & 0.460 & 0.456 & 66 & 0.113 & 0.112 \\
\hline 28 & 0.456 & 0.435 & 67 & 0.112 & 0.103 \\
\hline 29 & 0.435 & 0.411 & 68 & 0.103 & 0.105 \\
\hline 30 & 0.411 & 0.383 & 69 & 0.105 & 0.108 \\
\hline 31 & 0.383 & 0.357 & 70 & 0.108 & 0.096 \\
\hline 32 & 0.357 & 0.336 & 71 & 0.096 & 0.096 \\
\hline 33 & 0.336 & 0.315 & 72 & 0.096 & 0.107 \\
\hline 34 & 0.315 & 0.315 & 73 & 0.107 & 0.104 \\
\hline 35 & 0.315 & 0.321 & 74 & 0.104 & 0.106 \\
\hline 36 & 0.321 & 0.289 & 75 & 0.106 & 0.128 \\
\hline 37 & 0.289 & 0.255 & 76 & 0.128 & 0.131 \\
\hline 38 & 0.255 & 0.234 & 77 & 0.131 & 0.137 \\
\hline 39 & 0.234 & 0.197 & & & \\
\hline
\end{tabular}

Table 3. Performance measure of HONN with oil production ratio using single Lag1.

\begin{tabular}{|c|c|c|c|c|c|c|}
\hline \multirow{2}{*}{$\begin{array}{l}\text { Synaptic } \\
\text { Operation }\end{array}$} & \multirow{2}{*}{$\begin{array}{c}\text { Number } \\
\text { of } \\
\text { Hidden } \\
\text { Layers }\end{array}$} & \multirow{2}{*}{$\begin{array}{l}\text { Number } \\
\text { of } \\
\text { Neurons }\end{array}$} & \multicolumn{2}{|c|}{ RMSE } & \multicolumn{2}{|c|}{ MAPE } \\
\hline & & & Mean & SD & Mean & SD \\
\hline \multirow{5}{*}{$\begin{array}{c}\text { Linear } \\
\text { Synaptic } \\
\text { Operation }\end{array}$} & \multirow{5}{*}{1} & 1 & 0.068 & 0.002 & 15.932 & 2.635 \\
\hline & & 2 & 0.067 & 0.001 & 15.680 & 2.195 \\
\hline & & 3 & 0.067 & 0.001 & 16.379 & 2.471 \\
\hline & & 4 & 0.068 & 0.001 & 14.500 & 1.660 \\
\hline & & 5 & 0.067 & 0.001 & 13.863 & 0.442 \\
\hline \multirow{5}{*}{$\begin{array}{l}\text { Quadratic } \\
\text { Synaptic } \\
\text { Operation }\end{array}$} & \multirow{5}{*}{1} & 1 & 0.066 & 0.000 & 17.040 & 0.888 \\
\hline & & 2 & 0.067 & 0.001 & 18.370 & 2.575 \\
\hline & & 3 & 0.066 & 0.000 & 16.940 & 2.120 \\
\hline & & 4 & 0.067 & 0.001 & 16.554 & 0.840 \\
\hline & & 5 & 0.068 & 0.002 & 15.983 & 1.864 \\
\hline \multirow{5}{*}{$\begin{array}{c}\text { Cubic } \\
\text { Synaptic } \\
\text { Operation }\end{array}$} & \multirow{5}{*}{1} & 1 & 0.066 & 0.000 & 15.647 & 1.081 \\
\hline & & 2 & 0.066 & 0.000 & 15.295 & 2.092 \\
\hline & & 3 & 0.066 & 0.000 & 14.890 & 1.689 \\
\hline & & 4 & 0.067 & 0.002 & 16.742 & 2.676 \\
\hline & & 5 & 0.066 & 0.001 & 16.375 & 1.264 \\
\hline
\end{tabular}


Table 4. The train and test data used to train HONN model for scenario 2 (lag2)

\begin{tabular}{|c|c|c|c|c|c|}
\hline Months & Input & Target & Months & Input & Target \\
\hline 1 & 0.982 & 0.926 & 39 & 0.234 & 0.160 \\
\hline 2 & 0.954 & 0.871 & 40 & 0.197 & 0.161 \\
\hline 3 & 0.926 & 0.869 & 41 & 0.160 & 0.181 \\
\hline 4 & 0.871 & 0.873 & 42 & 0.161 & 0.194 \\
\hline 5 & 0.869 & 0.867 & 43 & 0.181 & 0.217 \\
\hline 6 & 0.873 & 0.880 & 44 & 0.194 & 0.234 \\
\hline 7 & 0.867 & 0.903 & 45 & 0.217 & 0.247 \\
\hline 8 & 0.880 & 0.871 & 46 & 0.234 & 0.233 \\
\hline 9 & 0.903 & 0.853 & 47 & 0.247 & 0.230 \\
\hline 10 & 0.871 & 0.851 & 48 & 0.233 & 0.214 \\
\hline 11 & 0.853 & 0.828 & 49 & 0.230 & 0.201 \\
\hline 12 & 0.851 & 0.789 & 50 & 0.214 & 0.184 \\
\hline 13 & 0.828 & 0.715 & 51 & 0.201 & 0.174 \\
\hline 14 & 0.789 & 0.640 & 52 & 0.184 & 0.156 \\
\hline 15 & 0.715 & 0.571 & 53 & 0.174 & 0.135 \\
\hline 16 & 0.640 & 0.515 & 54 & 0.156 & 0.130 \\
\hline 17 & 0.571 & 0.489 & 55 & 0.135 & 0.117 \\
\hline 18 & 0.515 & 0.507 & 56 & 0.130 & 0.112 \\
\hline 19 & 0.489 & 0.501 & 57 & 0.117 & 0.133 \\
\hline 20 & 0.507 & 0.477 & 58 & 0.112 & 0.155 \\
\hline 21 & 0.501 & 0.462 & 59 & 0.133 & 0.166 \\
\hline 22 & 0.477 & 0.455 & 60 & 0.155 & 0.175 \\
\hline 23 & 0.462 & 0.453 & 61 & 0.166 & 0.170 \\
\hline 24 & 0.455 & 0.447 & 62 & 0.175 & 0.152 \\
\hline 25 & 0.453 & 0.460 & 63 & 0.170 & 0.132 \\
\hline 26 & 0.447 & 0.456 & 64 & 0.152 & 0.113 \\
\hline 27 & 0.460 & 0.435 & 65 & 0.132 & 0.112 \\
\hline 28 & 0.456 & 0.411 & 66 & 0.113 & 0.103 \\
\hline 29 & 0.435 & 0.383 & 67 & 0.112 & 0.105 \\
\hline 30 & 0.411 & 0.357 & 68 & 0.103 & 0.108 \\
\hline 31 & 0.383 & 0.336 & 69 & 0.105 & 0.096 \\
\hline 32 & 0.357 & 0.315 & 70 & 0.108 & 0.096 \\
\hline 33 & 0.336 & 0.315 & 71 & 0.096 & 0.107 \\
\hline 34 & 0.315 & 0.321 & 72 & 0.096 & 0.104 \\
\hline 35 & 0.315 & 0.289 & 73 & 0.107 & 0.106 \\
\hline 36 & 0.321 & 0.255 & 74 & 0.104 & 0.128 \\
\hline 37 & 0.289 & 0.234 & 75 & 0.106 & 0.131 \\
\hline 38 & 0.255 & 0.197 & 76 & 0.128 & 0.137 \\
\hline
\end{tabular}

Table 5. Performance measure of HONN with oil production ratio using single lag2.

\begin{tabular}{|c|c|c|c|c|c|c|}
\hline \multirow{2}{*}{$\begin{array}{l}\text { Synaptic } \\
\text { Operation }\end{array}$} & \multirow{2}{*}{$\begin{array}{c}\text { Number } \\
\text { of } \\
\text { Hidden } \\
\text { Layers }\end{array}$} & \multirow{2}{*}{$\begin{array}{c}\text { Number } \\
\text { of } \\
\text { Neurons }\end{array}$} & \multicolumn{2}{|c|}{ RMSE } & \multicolumn{2}{|c|}{ MAPE } \\
\hline & & & Mean & $\mathrm{SD}$ & Mean & SD \\
\hline \multirow{5}{*}{$\begin{array}{c}\text { Linear } \\
\text { Synaptic } \\
\text { Operation }\end{array}$} & \multirow{5}{*}{1} & 1 & 0.082 & 0.003 & 19.182 & 1.392 \\
\hline & & 2 & 0.083 & 0.002 & 18.599 & 0.818 \\
\hline & & 3 & 0.083 & 0.002 & 18.985 & 1.224 \\
\hline & & 4 & 0.084 & 0.002 & 19.273 & 1.487 \\
\hline & & 5 & 0.080 & 0.004 & 21.345 & 1.785 \\
\hline \multirow{5}{*}{$\begin{array}{l}\text { Quadratic } \\
\text { Synaptic } \\
\text { Operation }\end{array}$} & \multirow{5}{*}{1} & 1 & 0.076 & 0.001 & 25.953 & 2.882 \\
\hline & & 2 & 0.076 & 0.001 & 24.899 & 2.202 \\
\hline & & 3 & 0.077 & 0.001 & 23.824 & 2.189 \\
\hline & & 4 & 0.079 & 0.003 & 21.624 & 3.454 \\
\hline & & 5 & 0.076 & 0.000 & 24.146 & 0.930 \\
\hline \multirow{5}{*}{$\begin{array}{c}\text { Cubic } \\
\text { Synaptic } \\
\text { Operation }\end{array}$} & \multirow{5}{*}{1} & 1 & 0.076 & 0.001 & 25.223 & 2.165 \\
\hline & & 2 & 0.078 & 0.001 & 21.822 & 1.798 \\
\hline & & 3 & 0.076 & 0.001 & 24.943 & 1.734 \\
\hline & & 4 & 0.076 & 0.000 & 25.745 & 0.716 \\
\hline & & 5 & 0.078 & 0.004 & 23.315 & 1.930 \\
\hline
\end{tabular}


Table 6. The train and test data used to train HONN model for scenario 3 (accumulated lag2)

\begin{tabular}{|c|c|c|c|c|c|c|c|}
\hline Months & $\begin{array}{c}\text { Input- } \\
1 \\
\end{array}$ & $\begin{array}{c}\text { Input- } \\
2 \\
\end{array}$ & Target & Months & $\begin{array}{c}\text { Input- } \\
1 \\
\end{array}$ & $\begin{array}{c}\text { Input- } \\
2 \\
\end{array}$ & Target \\
\hline 1 & 0.982 & 0.954 & 0.926 & 39 & 0.234 & 0.197 & 0.160 \\
\hline 2 & 0.954 & 0.926 & 0.871 & 40 & 0.197 & 0.160 & 0.161 \\
\hline 3 & 0.926 & 0.871 & 0.869 & 41 & 0.160 & 0.161 & 0.181 \\
\hline 4 & 0.871 & 0.869 & 0.873 & 42 & 0.161 & 0.181 & 0.194 \\
\hline 5 & 0.869 & 0.873 & 0.867 & 43 & 0.181 & 0.194 & 0.217 \\
\hline 6 & 0.873 & 0.867 & 0.880 & 44 & 0.194 & 0.217 & 0.234 \\
\hline 7 & 0.867 & 0.880 & 0.903 & 45 & 0.217 & 0.234 & 0.247 \\
\hline 8 & 0.880 & 0.903 & 0.871 & 46 & 0.234 & 0.247 & 0.233 \\
\hline 9 & 0.903 & 0.871 & 0.853 & 47 & 0.247 & 0.233 & 0.230 \\
\hline 10 & 0.871 & 0.853 & 0.851 & 48 & 0.233 & 0.230 & 0.214 \\
\hline 11 & 0.853 & 0.851 & 0.828 & 49 & 0.230 & 0.214 & 0.201 \\
\hline 12 & 0.851 & 0.828 & 0.789 & 50 & 0.214 & 0.201 & 0.184 \\
\hline 13 & 0.828 & 0.789 & 0.715 & 51 & 0.201 & 0.184 & 0.174 \\
\hline 14 & 0.789 & 0.715 & 0.640 & 52 & 0.184 & 0.174 & 0.156 \\
\hline 15 & 0.715 & 0.640 & 0.571 & 53 & 0.174 & 0.156 & 0.135 \\
\hline 16 & 0.640 & 0.571 & 0.515 & 54 & 0.156 & 0.135 & 0.130 \\
\hline 17 & 0.571 & 0.515 & 0.489 & 55 & 0.135 & 0.130 & 0.117 \\
\hline 18 & 0.515 & 0.489 & 0.507 & 56 & 0.130 & 0.117 & 0.112 \\
\hline 19 & 0.489 & 0.507 & 0.501 & 57 & 0.117 & 0.112 & 0.133 \\
\hline 20 & 0.507 & 0.501 & 0.477 & 58 & 0.112 & 0.133 & 0.155 \\
\hline 21 & 0.501 & 0.477 & 0.462 & 59 & 0.133 & 0.155 & 0.166 \\
\hline 22 & 0.477 & 0.462 & 0.455 & 60 & 0.155 & 0.166 & 0.175 \\
\hline 23 & 0.462 & 0.455 & 0.453 & 61 & 0.166 & 0.175 & 0.170 \\
\hline 24 & 0.455 & 0.453 & 0.447 & 62 & 0.175 & 0.170 & 0.152 \\
\hline 25 & 0.453 & 0.447 & 0.460 & 63 & 0.170 & 0.152 & 0.132 \\
\hline 26 & 0.447 & 0.460 & 0.456 & 64 & 0.152 & 0.132 & 0.113 \\
\hline 27 & 0.460 & 0.456 & 0.435 & 65 & 0.132 & 0.113 & 0.112 \\
\hline 28 & 0.456 & 0.435 & 0.411 & 66 & 0.113 & 0.112 & 0.103 \\
\hline 29 & 0.435 & 0.411 & 0.383 & 67 & 0.112 & 0.103 & 0.105 \\
\hline 30 & 0.411 & 0.383 & 0.357 & 68 & 0.103 & 0.105 & 0.108 \\
\hline 31 & 0.383 & 0.357 & 0.336 & 69 & 0.105 & 0.108 & 0.096 \\
\hline 32 & 0.357 & 0.336 & 0.315 & 70 & 0.108 & 0.096 & 0.096 \\
\hline 33 & 0.336 & 0.315 & 0.315 & 71 & 0.096 & 0.096 & 0.107 \\
\hline 34 & 0.315 & 0.315 & 0.321 & 72 & 0.096 & 0.107 & 0.104 \\
\hline 35 & 0.315 & 0.321 & 0.289 & 73 & 0.107 & 0.104 & 0.106 \\
\hline 36 & 0.321 & 0.289 & 0.255 & 74 & 0.104 & 0.106 & 0.128 \\
\hline 37 & 0.289 & 0.255 & 0.234 & 75 & 0.106 & 0.128 & 0.131 \\
\hline 38 & 0.255 & 0.234 & 0.197 & 76 & 0.128 & 0.131 & 0.137 \\
\hline
\end{tabular}

Table 7. Performance measure of HONN with oil production ratio using accumulated lag2

\begin{tabular}{|c|c|c|c|c|c|c|}
\hline \multirow{2}{*}{$\begin{array}{c}\text { Synaptic } \\
\text { Operatio } \\
n\end{array}$} & \multirow{2}{*}{$\begin{array}{c}\text { Numb } \\
\text { er of } \\
\text { Hidde } \\
n \\
\text { Layer }\end{array}$} & \multirow{2}{*}{$\begin{array}{l}\text { Numbe } \\
\text { r of } \\
\text { Neuron } \\
\text { s }\end{array}$} & \multicolumn{2}{|c|}{ RMSE } & \multicolumn{2}{|c|}{ MAPE } \\
\hline & & & $\begin{array}{c}\text { Mea } \\
\mathrm{n}\end{array}$ & SD & Mean & $\mathrm{SD}$ \\
\hline \multirow{10}{*}{$\begin{array}{c}\text { Linear } \\
\text { Synaptic } \\
\text { Operatio } \\
n\end{array}$} & \multirow{10}{*}{1} & & 0.07 & 0.00 & 15.15 & 1.59 \\
\hline & & 1 & 1 & 5 & 3 & 8 \\
\hline & & & 0.06 & 0.00 & 13.67 & 1.06 \\
\hline & & 2 & 7 & 3 & 1 & 8 \\
\hline & & & 0.07 & 0.00 & 14.71 & 1.17 \\
\hline & & 3 & 2 & 4 & 4 & 0 \\
\hline & & & 0.06 & 0.00 & 16.02 & 2.60 \\
\hline & & 4 & 9 & 7 & 5 & 6 \\
\hline & & & 0.06 & 0.00 & 14.57 & 1.00 \\
\hline & & 5 & 9 & 2 & 5 & 0 \\
\hline \multirow{10}{*}{$\begin{array}{c}\text { Quadrati } \\
\text { c } \\
\text { Synaptic } \\
\text { Operatio } \\
\text { n }\end{array}$} & \multirow{10}{*}{1} & & 0.06 & 0.00 & 16.65 & 1.67 \\
\hline & & 1 & 4 & 2 & 1 & 0 \\
\hline & & & 0.06 & 0.00 & 18.08 & 2.72 \\
\hline & & 2 & 9 & 3 & 3 & 0 \\
\hline & & & 0.06 & 0.00 & 17.30 & 1.77 \\
\hline & & 3 & 9 & 2 & 2 & 7 \\
\hline & & & 0.06 & 0.00 & 16.25 & 2.20 \\
\hline & & 4 & 9 & 4 & 0 & 4 \\
\hline & & & 0.06 & 0.00 & 16.22 & 3.49 \\
\hline & & 5 & 5 & 4 & 9 & 2 \\
\hline \multirow{10}{*}{$\begin{array}{c}\text { Cubic } \\
\text { Synaptic } \\
\text { Operatio } \\
\text { n }\end{array}$} & \multirow{10}{*}{1} & & 0.06 & 0.00 & 18.18 & 1.83 \\
\hline & & 1 & 6 & 4 & 9 & 4 \\
\hline & & & 0.07 & 0.00 & 15.31 & 0.96 \\
\hline & & 2 & 1 & 4 & 5 & 4 \\
\hline & & & 0.07 & 0.00 & 16.75 & 1.56 \\
\hline & & 3 & 0 & 4 & 9 & 3 \\
\hline & & & 0.07 & 0.00 & 17.03 & 1.78 \\
\hline & & 4 & 0 & 9 & 4 & 0 \\
\hline & & & 0.07 & 0.00 & 16.40 & 2.91 \\
\hline & & 5 & 0 & 6 & 7 & 4 \\
\hline
\end{tabular}

Table 8. Most significant input variable selected based on CCF of monthly production data

Cross-Correlation Variables

Significant lags

\begin{tabular}{c|c} 
Oil-Oil & $\operatorname{lag} 1$ \\
Oil-Gas & $\operatorname{lag} 1, \operatorname{lag} 2$ \\
Oil-Water & $\operatorname{lag} 23$
\end{tabular}


Table 10. Performance measure of HONN with oil, gas and water production ratio.

\begin{tabular}{|c|c|c|c|c|c|c|}
\hline \multirow{2}{*}{$\begin{array}{l}\text { Synaptic } \\
\text { Operation }\end{array}$} & \multirow{2}{*}{$\begin{array}{c}\text { Number } \\
\text { of } \\
\text { Hidden } \\
\text { Layers }\end{array}$} & \multirow{2}{*}{$\begin{array}{l}\text { Number } \\
\text { of } \\
\text { Neurons }\end{array}$} & \multicolumn{2}{|c|}{ RMSE } & \multicolumn{2}{|c|}{ MAPE } \\
\hline & & & Mean & SD & Mean & SD \\
\hline \multirow{5}{*}{$\begin{array}{c}\text { Linear } \\
\text { Synaptic } \\
\text { Operation } \\
\text { (LSO) }\end{array}$} & \multirow{5}{*}{1} & 1 & 0.068 & 0.005 & 17.896 & 3.547 \\
\hline & & 2 & 0.071 & 0.003 & 17.863 & 3.846 \\
\hline & & 3 & 0.076 & 0.004 & 17.951 & 1.533 \\
\hline & & 4 & 0.070 & 0.006 & 18.563 & 4.083 \\
\hline & & 5 & 0.068 & 0.005 & 20.223 & 1.955 \\
\hline \multirow{5}{*}{$\begin{array}{c}\text { Quadratic } \\
\text { Synaptic } \\
\text { Operation } \\
\text { (QSO) }\end{array}$} & \multirow{5}{*}{1} & 1 & 0.065 & 0.003 & 15.612 & 0.765 \\
\hline & & 2 & 0.061 & 0.010 & 15.853 & 1.541 \\
\hline & & 3 & 0.064 & 0.006 & 15.953 & 2.439 \\
\hline & & 4 & 0.069 & 0.007 & 15.128 & 0.475 \\
\hline & & 5 & 0.071 & 0.011 & 18.358 & 1.076 \\
\hline \multirow{5}{*}{$\begin{array}{c}\text { Cubic } \\
\text { Synaptic } \\
\text { Operation } \\
(\mathrm{CSO})\end{array}$} & \multirow{5}{*}{1} & 1 & 0.070 & 0.002 & 17.034 & 0.749 \\
\hline & & 2 & 0.076 & 0.007 & 16.073 & 1.684 \\
\hline & & 3 & 0.078 & 0.005 & 19.214 & 0.776 \\
\hline & & 4 & 0.074 & 0.002 & 16.363 & 0.774 \\
\hline & & 5 & 0.054 & 0.008 & 17.906 & 1.047 \\
\hline
\end{tabular}

Table 9. The train and test data used for training HONN model for case study-2

\begin{tabular}{|c|c|c|c|c|c|}
\hline Months & Input-1 & Input-2 & Input-3 & Input-4 & Target \\
\hline 1 & 0.462 & 0.324 & 0.334 & 0.096 & 0.455 \\
\hline 2 & 0.455 & 0.319 & 0.324 & 0.159 & 0.453 \\
\hline 3 & 0.453 & 0.317 & 0.319 & 0.173 & 0.447 \\
\hline 4 & 0.447 & 0.313 & 0.317 & 0.168 & 0.46 \\
\hline 5 & 0.46 & 0.303 & 0.313 & 0.153 & 0.456 \\
\hline 6 & 0.456 & 0.288 & 0.303 & 0.12 & 0.435 \\
\hline 7 & 0.435 & 0.263 & 0.288 & 0.082 & 0.411 \\
\hline 8 & 0.411 & 0.236 & 0.263 & 0.064 & 0.383 \\
\hline 9 & 0.383 & 0.208 & 0.236 & 0.106 & 0.357 \\
\hline 10 & 0.357 & 0.2 & 0.208 & 0.16 & 0.336 \\
\hline 11 & 0.336 & 0.196 & 0.2 & 0.175 & 0.315 \\
\hline 12 & 0.315 & 0.189 & 0.196 & 0.19 & 0.315 \\
\hline 13 & 0.315 & 0.193 & 0.189 & 0.202 & 0.321 \\
\hline 14 & 0.321 & 0.201 & 0.193 & 0.181 & 0.289 \\
\hline 15 & 0.289 & 0.179 & 0.201 & 0.224 & 0.255 \\
\hline 16 & 0.255 & 0.155 & 0.179 & 0.275 & 0.234 \\
\hline 17 & 0.234 & 0.143 & 0.155 & 0.322 & 0.197 \\
\hline 18 & 0.197 & 0.122 & 0.143 & 0.375 & 0.16 \\
\hline 19 & 0.16 & 0.1 & 0.122 & 0.423 & 0.161 \\
\hline 20 & 0.161 & 0.107 & 0.1 & 0.422 & 0.181 \\
\hline 21 & 0.181 & 0.12 & 0.107 & 0.45 & 0.194 \\
\hline 22 & 0.194 & 0.126 & 0.12 & 0.514 & 0.217 \\
\hline 23 & 0.217 & 0.139 & 0.126 & 0.513 & 0.234 \\
\hline 24 & 0.234 & 0.149 & 0.139 & 0.535 & 0.247 \\
\hline 25 & 0.247 & 0.158 & 0.149 & 0.527 & 0.233 \\
\hline 26 & 0.233 & 0.149 & 0.158 & 0.564 & 0.23 \\
\hline 27 & 0.23 & 0.151 & 0.149 & 0.559 & 0.214 \\
\hline 28 & 0.214 & 0.145 & 0.151 & 0.628 & 0.201 \\
\hline 29 & 0.201 & 0.139 & 0.145 & 0.649 & 0.184 \\
\hline 30 & 0.184 & 0.129 & 0.139 & 0.678 & 0.174 \\
\hline 31 & 0.174 & 0.122 & 0.129 & 0.665 & 0.156 \\
\hline 32 & 0.156 & 0.107 & 0.122 & 0.67 & 0.135 \\
\hline 33 & 0.135 & 0.091 & 0.107 & 0.658 & 0.13 \\
\hline 34 & 0.13 & 0.087 & 0.091 & 0.712 & 0.117 \\
\hline 35 & 0.117 & 0.079 & 0.087 & 0.728 & 0.112 \\
\hline 36 & 0.112 & 0.077 & 0.079 & 0.732 & 0.133 \\
\hline 37 & 0.133 & 0.091 & 0.077 & 0.681 & 0.155 \\
\hline 38 & 0.155 & 0.105 & 0.091 & 0.637 & 0.166 \\
\hline 39 & 0.166 & 0.112 & 0.105 & 0.536 & 0.175 \\
\hline 40 & 0.175 & 0.117 & 0.112 & 0.479 & 0.17 \\
\hline 41 & 0.17 & 0.114 & 0.117 & 0.425 & 0.152 \\
\hline 42 & 0.152 & 0.1 & 0.114 & 0.422 & 0.132 \\
\hline 43 & 0.132 & 0.086 & 0.1 & 0.498 & 0.113 \\
\hline 44 & 0.113 & 0.073 & 0.086 & 0.541 & 0.112 \\
\hline 45 & 0.112 & 0.071 & 0.073 & 0.631 & 0.103 \\
\hline 46 & 0.103 & 0.066 & 0.071 & 0.731 & 0.105 \\
\hline 47 & 0.105 & 0.069 & 0.066 & 0.84 & 0.108 \\
\hline 48 & 0.108 & 0.072 & 0.069 & 0.802 & 0.096 \\
\hline 49 & 0.096 & 0.065 & 0.072 & 0.813 & 0.096 \\
\hline 50 & 0.096 & 0.067 & 0.065 & 0.767 & 0.107 \\
\hline 51 & 0.107 & 0.076 & 0.067 & 0.703 & 0.104 \\
\hline 52 & 0.104 & 0.074 & 0.076 & 0.65 & 0.106 \\
\hline 53 & 0.106 & 0.076 & 0.074 & 0.662 & 0.128 \\
\hline 54 & 0.128 & 0.092 & 0.076 & 0.69 & 0.131 \\
\hline 55 & 0.131 & 0.094 & 0.092 & 0.717 & 0.137 \\
\hline
\end{tabular}




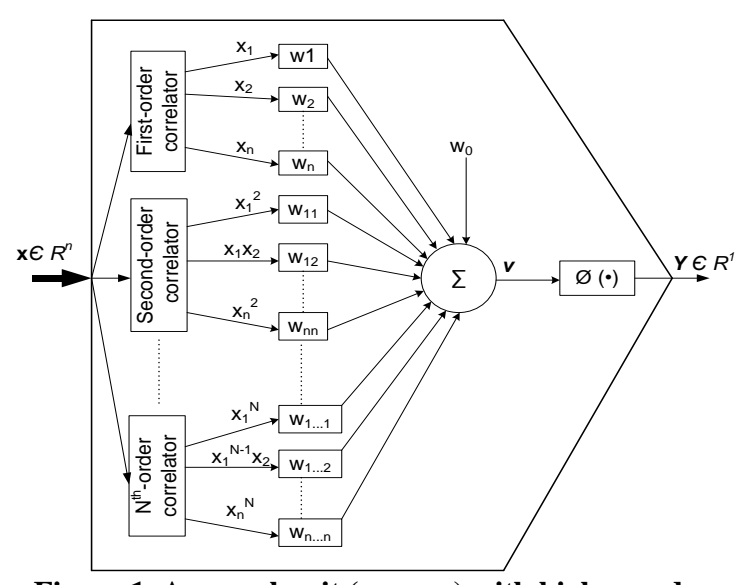

Figure 1. A neural unit (neuron) with higher-order synaptic operation (HOSO) ${ }^{[14]}$.

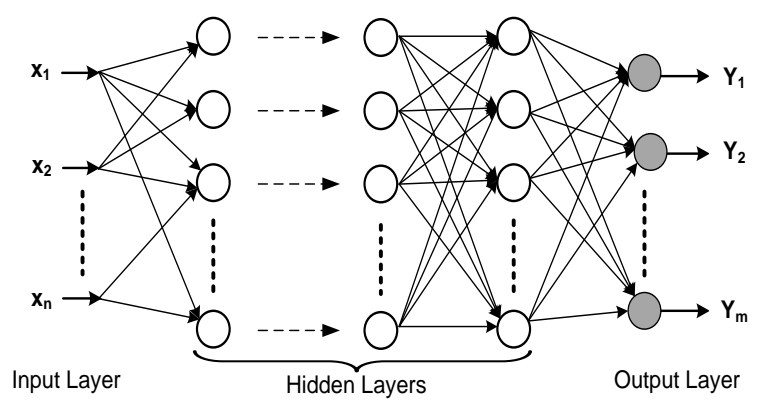

Figure 2. A schematic diagram of HONN with multilayer.

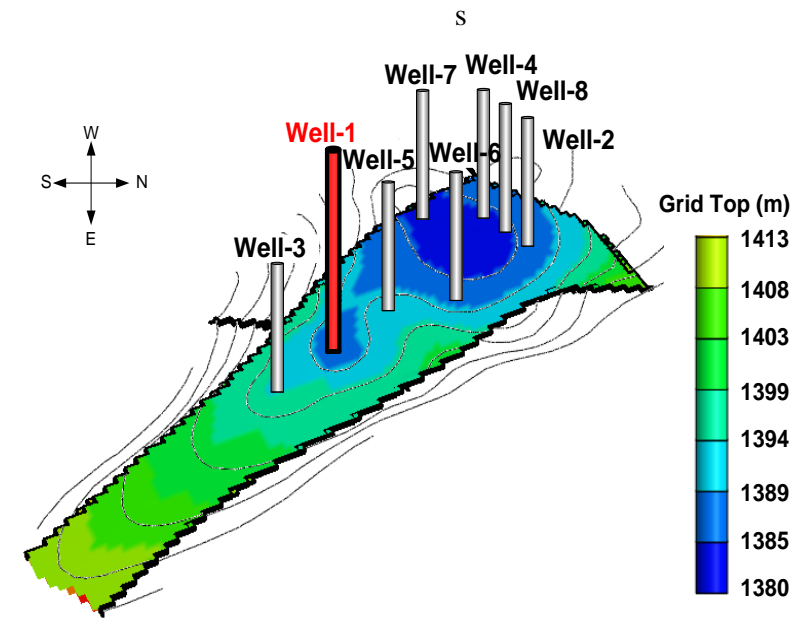

Figure 3. The top structure map of the oil bearing reservoir with well locations. In this case study, the oil production from Well-1 is forecasted.

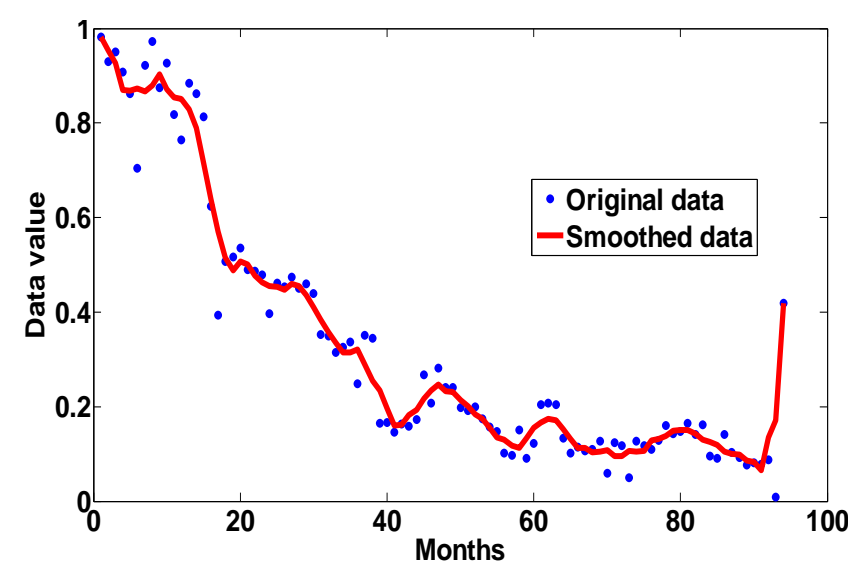

Figure 4. Oil production history of Well-1 from 2001 2009

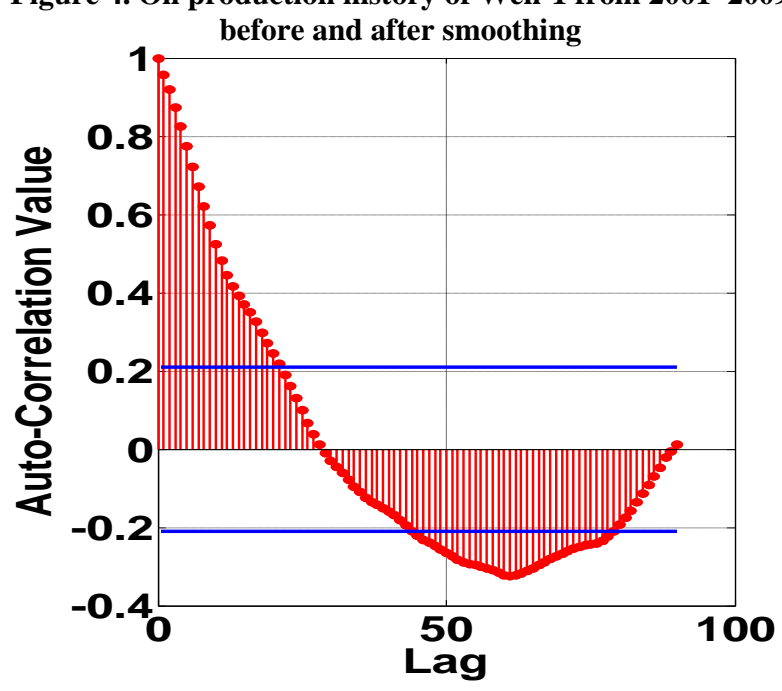

Figure 5. ACF of oil production after pre-processing. The blue line represents the confidential level of correlation (outside of the line represents $95 \%$ of confidence).
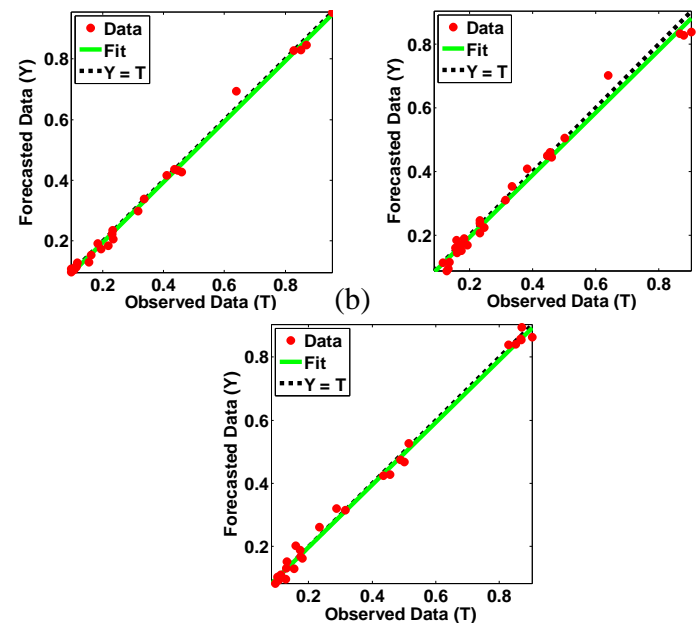

(c)

Figure 6. Regression of validation set of HONN with (a)

LSO having 5 neurons in the hidden layer, (b) QSO having 5 neurons in the hidden layer (c) CSO having three neurons in the hidden layer. 
(a)

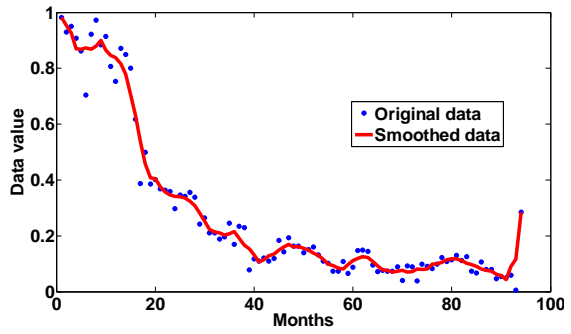

(b)

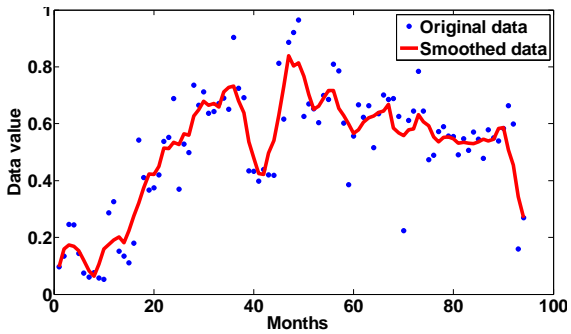

Figure 7. (a) Gas production data from Well-1 before and after smoothing (b) Water production from Well-1 before and after smoothing.

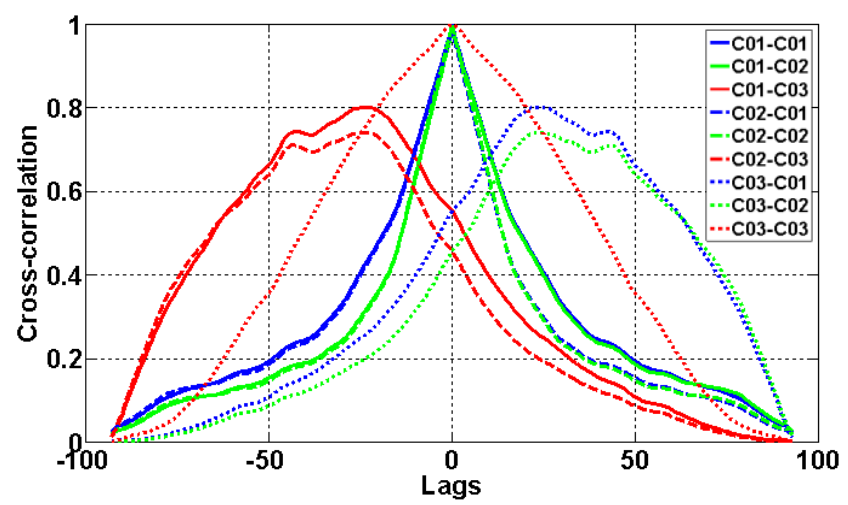

Figure 8. CCF of smoothed oil, gas and water production data. The legend represents the correlation between two parameters; notation inside the legend box $\mathrm{C01}, \mathrm{CO2}$ and $\mathrm{C03}$ represent oil, gas and water respectively.

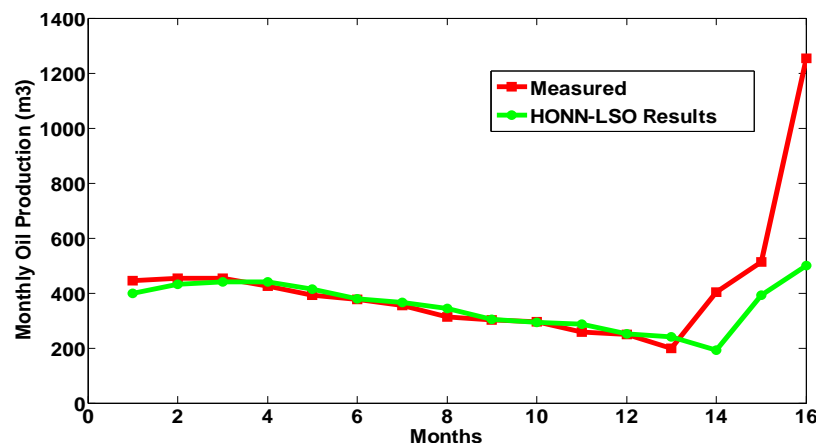

Figure 9. Comparison between the actual oil production and the forecasted results from HONN with LSO using single lag- 1 from case study-1. 